\title{
The Effect of Renewable Energy Development, Market Regulation, and Technological Innovation on CO2 Emission in BRICS Countries
}

Shah Abbas ( $\sim$ sabbasnagri@gmail.com )

Gongqing Institute of Science and Technology https://orcid.org/0000-0002-5861-4262

Peng Gui

Gongqing Institute of Science and Technology

Chen Ai

Nanchang University

Najabat Ali

Jiangsu University

Research Article

Keywords: Renewable energy, market regulation, technological innovation, carbon emissions

Posted Date: December 16th, 2021

DOI: https://doi.org/10.21203/rs.3.rs-1120763/v1

License: (c) (i) This work is licensed under a Creative Commons Attribution 4.0 International License.

Read Full License 


\title{
1 The effect of renewable energy development, market regulation, and technological 2 innovation on $\mathrm{CO}_{2}$ emission in BRICS countries
} \\ a, Corresponding author \\ Shah Abbas ${ }^{\mathrm{a}}$ \\ Gongqing Institute of Science and Technology, Jiangxi Province, 332020, China \\ Email: sabbasnagri@gmail.com \\ Peng Gui \\ Gongqing Institute of Science and Technology, Jiangxi Province, 332020, China \\ Email: 1129299735@qq.com

\section{Chen Ai} \\ School of Software Nanchang University, Jiangxi, 332020, China \\ Email: lisa6606@126.com \\ Najabat Ali \\ School of Finance and Economics, Jiangsu University, Zhenjiang, 212013, China \\ Email: alinajabat@hotmail.com
}

\section{Abstract}

The relationship between energy, environment, and economic growth has been received a lot of attention recently among scientific studies, but environmental sustainability remains a global issue. Renewable energy production, technological advancement, and regulatory policy mechanisms can all help to reduce greenhouse gas emissions and support environmental sustainability. The purpose of this study was to look at the influence of renewable energy development, market regulation, and technological innovation on carbon emissions in the BRICS countries. Renewable energy development is measured by the contribution of renewables to the total primary energy supply. The market regulation represents the measure of environmental regulation policies that the state administrative department uses to manage or limit pollution. Technological innovation is measured by environment-related technologies. To examine the symmetric and asymmetric relationship between study variables, we used a second-generation panel unit root test, linear and nonlinear co-integration tests, and linear and nonlinear ARDL. Using a symmetric approach, we

27 found that renewable energy development, technological innovation, and market-based environmental regulation policies had a considerable positive impact on lowering carbon emissions (CE). Furthermore, the combined effect of market regulation and renewable energy development, as well as market regulation and technology innovation on CE is negative and significant. In the asymmetric specification, we found that positive and negative shocks are not uniform but vary according to ascending and descending movement in the primary variables. In nonlinear specification, the long run effects are higher than the short run. The study suggests renewable energy development, technical innovation, and market-based regulation environmental policies are the main mechanisms to reduce carbon emission in BRICS countries.

Keywords: Renewable energy, market regulation, technological innovation, carbon emissions 


\section{Introduction}

37 The nexus between energy, environment, and economic growth has been studied extensively among scientific studies and research scholars, but environmental sustainability and economic growth is remaining one of the biggest challenging issue to global community. Many countries adopt the new growth models and try to boost economic growth, and foreign competitiveness by increasing industrial and manufacturing production. Studies indicates that the extensive use of fossil fuel energy resources for industrial and manufacturing production is the primary source of carbon dioxide emissions cause global warming and climate change (Liu and Xiao 2018; Mi et al. 2018). There is wide consensus among scientific studies and research scholars that renewable energy is a viable alternative to fossil fuels energy for achieving sustainable development goals (Dogan and Ozturk 2017; Shuai et al. 2017). Widespread use of renewable energy resources is vital to achieving sustainable development goals and is considered secure, costeffective, and environmentally sustainable options to underpin economic and social development (Breyer et al. 2020). Several studies and policy reports emphasized that the role of renewable energy resources, including solar energy, wind, tide, biofuel, hydroelectricity, and geothermal, which diversifying renewable energy supply as well as mitigating environmental and energy issues (Mert et al. 2019; REN21 2018; Zaidi et al. 2019). Renewable energy resources are not only essential in limiting $\mathrm{CO}_{2}$ emissions, but they are also crucial in contributing to the economy in a sustainable manner (Dong et al. 2018; Shahbaz et al. 2017). Thus, apart from the contribution of renewable energy resources to reducing $\mathrm{CO}_{2}$ emissions, it also positively contributes to the economy and promotes environmental quality (Breyer et al. 2020; Damette and Marques 2019; Moutinho et al. 2018). Therefore, promoting renewable energy will help to boost economic development, improve environmental quality, and improve energy efficiency (Dechezleprêtre and Sato 2017).

Thus, it is important to focus more attention at the national, regional and global level on reducing usage of traditional non-renewable energy resources and prioritize the adaptation of renewable energy resources to achieve sustainable development goals. Many countries throughout the world are striving to convert their fossil fuel energy consumption to renewable sources, and are enacting renewable energy resource policies both individually and as part of a worldwide network to minimize $\mathrm{CO} 2$ emissions. For instance, Peru has set a goal of generating $60 \%$ of its electricity from renewable energy by 2024 . Norway and Iceland are now generating $100 \%$ of their electricity from renewable sources. Germany and Sweden have also claimed that they would be carbon-free by 2050 (Al-Mahrouqi and Amin 2014; Dean et al. 2016). At the same time, the Organization of Economic Cooperation and Development (OECD), the International Energy Agency (IEA), the Center for Climate and Energy Solution (C2ES), and the International Renewable Energy Agency (IRENA) also play a significant role in designing market regulation policies for renewable energy development. The United Nations General Assembly (UNGA) established the Sustainable Development Goals (SDGs) in 2015, which also provide a powerful basis for international collaboration to achieve a sustainable future for the world. The goals include three key objectives: ensuring sustainable, secure, and universal access to modern energy; significantly increasing the use of renewable energy; and doubling the global energy efficiency rate (Bank et al. 2017). Thus, preserving environmental protection has become one of the world's most

71 challenging issue and requiring stricter environmental norms and regulations to be implemented (Costa-Campi et al.

72 2017; Jardón et al. 2017; Sheffield and Landrigan 2011; Wolde-Rufael and Weldemeskel 2020). 
A number of empirical studies have explored the causes of pollutant emissions and assessed the impact of renewable energy resources in reducing $\mathrm{CO} 2$ emissions at regional and global levels., using a range of quantitative methods. Despite all these measures and policies, $\mathrm{CO}_{2}$ emissions are growing and one of the major environmental problems. It is necessary to identify the main factors reduce the pollution emissions and promoting renewable energy development. Therefore, this study is designed to identify the factor and empirically investigate the impact of renewable energy development, market regulations, and technological innovation on carbon emissions in BRICS (Brazil, Russia, India, China, and South Africa) countries over the period 1990-2018. There are two main factors that motivate to conduct current study on BRICS countries. Frist, the BRIC countries comprised $40 \%$ of the total world population and are considered the fastest-growing countries in terms of population, economic growth, and development around the world (Chen and De Lombaerde 2014). Among these countries, India and China are considered the largest economies in population growth and leading suppliers of manufacturing goods and services. Brazil and Russian are considered the largest raw material suppliers in the world manufacturing market. Second, the BRICS countries' economic expansion is predominantly driven by high-energy-consuming industries such as building, mining, and manufacturing, resulting in increased $\mathrm{CO} 2$ emissions (Cowan et al. 2014).

This research makes a contribution to the growing literature on sustainable renewable energy development in multifaceted ways; Frist, the novelty of present study is that it investigates the role of renewable energy development in reducing $\mathrm{CO}_{2}$ emissions. Second, novelty of current study is that it takes into account the role of market based environmental-regulation polices and technological innovation in reducing $\mathrm{CO}_{2}$ emissions. Third, the study used most recent developed panel econometric methods to investigate the impact of renewable energy development, market regulation, and technological innovation on $\mathrm{CO}_{2}$ emissions. This can help to provide accurate and robustness insights into the policymaking process for mitigating pollutant emissions across the five BRICS countries.

Apart from the introduction, the current study is divided into four sections. In the second section, we look at renewable energy resources in the BRIC countries. The third section is about relevant literature on renewable energy consumption, market regulation, and the role of technology innovation. Further, discuss the role of policies in promoting renewable energy consumption. In the fourth section, data and methodology are described. The empirical findings and discussions are presented in the fifth section. The study's results are summarized in the final section, along with policy recommendations.

\section{Overview of BRICS Countries}

101 The BRICS countries are comprised of five developing countries: Brazil, Russia, India, China, and South Africa 102 (Pathak and Shah 2019). These countries have different economic, political and social characteristics with different 103 population growth, energy consumption patterns and production, urban and infrastructure development, and industrial 104 structure. The BRICS countries conquer 30\% of the global land, $40 \%$ of the global population, and contribute more than $50 \%$ to the global GDP. However, over the past decades, it is witnessed that rapid economic growth and economic prosperity of BRICS countries significantly influence the global environment. The over increased fossil fuel consumption and greenhouse gas emissions in BRICs countries enforced to switch from fossil fuel to renewable energy resources. The demand for renewable energy resources (wind, solar, and hydropower) has increased and grown rapidly in the BRICS countries over the last two decades. The countries have rich abundant in renewable energy resources. 
For example, China's wind resources in Inner Mongolia are vast, and biomass energy is a major source of energy in rural areas (Meisen and Hawkins 2009). India is a tropical country with average temperatures ranging from 25 to 27 degrees Celsius. The country receives 5000 trillion $\mathrm{kW}$ equivalent in solar energy; the climate is ideal for solar energy development. Russia is the world's largest country in terms of land area. Mineral resources abound in the region, which exports and consumes a significant amount of fossil fuel each year. Russia is considering the third and largest producer and consumer of energy resources with $10 \%$ of world production and 5\% energy consumption after the United States and China (Bächtold 2012). Brazil is the world's sixth-largest green energy stockholder (Pathak and Shah 2019). The country has abundant agricultural resources, mineral reserves, and clean-energy hydroelectric resources. In 2014, renewable energy accounted for $75 \%$ of total energy production in Brazil, with hydropower accounting for $90 \%$ of total electricity generation (Dudley 2018) . The contribution of wind power remained relatively low. South Africa is smaller population and economy as compare to other BRICS countries. "The country is enriched with natural reserves such as coal, natural gas, and gold and diamond. South Africa is ideal for solar energy resources, the UNEP reports claimed that the country will get 50\% of its electricity from renewable energy resources by 2030 (Global 2017)."

\section{Review of Literature}

\section{Renewable energy development and CO2 emission}

125 Developing renewable energy resources has become a critical component of combating global climate change, 126 reducing greenhouse gas emissions, and preserving the environment. Several scientific studies investigate the impact of renewable energy resources on carbon emissions by using diverse econometric methods and different datasets. For example, Wang et al. (2018) investigated the factors regulating renewable energy growth, energy security, and carbon emissions in China using the Divisia index approach. They used the Grey relational model to confirm the relation between renewable energy and its drivers. The findings suggest that energy security has a substantial influence on the development of renewable energy. They claimed that robust and sustained RE policies will enable China in attaining its long-term energy policy objectives.

Zeng et al. (2017) survey the historical renewable development in BRICS countries from 1992 to 2011. According to the study, China, India, and Brazil have a better track record and a greater number of achievements than Russia and South Africa. After decades of hard work, China has mastered a variety of innovative clean energy technologies, while installed capacity in India and Brazil is quickly rising. Russia and South Africa, on the other hand, are committed to growing their renewable energy industries. The study brought attention to a few critical challenges in the development of renewable energy in the BRICS countries. The key challenges include a lack of finance, a lack of investment in small and medium-sized enterprises, and inefficient government initiatives.

In more recent studies research highlight, the factors that have influenced the production and usage of renewable energy resources. For example, Wang et al. (2020) investigate the regional renewable energy development across the 29 provinces in China. The study constructed a multidimensional measure of renewable energy development

143 in China from 2008 to 2014 using a dynamic principal component analysis tool. They developed a quantitative

144 assessment system and implemented the multidimensional approach. They choose five-dimensional variables such as

145 the economy, institutions, technical development potentials, energy security and environmental conservation, and the renewable energy market. The empirical findings show that renewable energy development varies greatly across 
147 China's regions. The more economically developed areas, such as Beijing, Shanghai, and Guangdong, have high 148 rankings and consistent advantages in all dimensions. Renewable energy development is at its peak in Beijing and 149 Shanghai while Guangdong, Zhejiang, Jiangsu, and Tianjin are at second place. At the same time, western provinces 150 such as Ningxia, Qinghai, and Guizhou have the lowest renewable energy development over the entire sample period. 151 They came to the conclusion that China's institutional policies, as well as the position and economic foundations of 152 the government are more relevant and play a significant role in energy security, environmental protection, renewable energy production, and $\mathrm{CO} 2$ emissions reduction.

Banday and Aneja (2020) examine the causal link between renewable and fossil fuel energy, economic development, and carbon emissions in BRICS countries over the 1990-2017. They "used bootstrap Dumitrescu and Hurlin (2012) panel causality test for heterogeneity and dependency in cross-sectional units across the sample countries. The findings indicate that India, China, Brazil, and South Africa have unidirectional causality from GDP to $\mathrm{CO}_{2}$ emissions, whereas Russia has no causality. In comparison, the causality from renewable energy to GDP shows that GDP growth causes renewable energy in India, China, Brazil, and Russia and not causality” for South Africa. This implies that GDP growth is an important driving factor in both $\mathrm{CO}_{2}$ emissions and renewable energy. Theoretically, the results support the Environmental Kuznets Curve (EKC) hypothesis, which predicts an inverted Ushaped relationship between income and environmental indicators. Thus, in the long run, renewable energy development is one of the most important solutions to an environmental problem.

Khan et al. (2020) investigate the relationship between energy usage, economic development, and $\mathrm{CO}_{2}$ emissions in Pakistan using annual time series data from 1965 to 2015. They used the autoregressive distributed lag model (ARDL), and the estimated results show that in the short and long run energy use and economic growth increase

$167 \mathrm{CO}_{2}$ emissions. They claimed that renewable energy resources would replace conventional energy sources, lowering $168 \mathrm{CO}_{2}$ emissions and ensuring Pakistan's long-term economic development.

Balakrishnan et al. (2020) analyzed the renewable energy installed capacity of developing countries emphasizing on China as a leader in RE development. They addressed the legislation and policies surrounding the use of renewable energy. The study found that the most significant impediment to RE development in developing

172 countries is the private sector's inability to invest due to the long time it takes for capital to return and the high cost.

173 The study suggested that government plays a significant role in resolving this issue through the support and guaranteed purchase generated of electricity.

Saidi and Omri (2020) examined the short and long-run impact of renewable energy and nuclear energy consumption on $\mathrm{CO}_{2}$ emissions in 15 OECD countries from 1990 to 2015. The study used a Fully Modified OLS (FMOLD) and vector error correction (VECM) approach. The overall panel estimation results show both renewable and nuclear energy reduces $\mathrm{CO}_{2}$ emission. While in the case of a single country, FMOLS shows mixed results. $\mathrm{CO}_{2}$ 179 emissions increase in Netherland and South Korea with an investment in renewable and non-renewable energy sectors. 180 In some countries like Canada, Japan, France, Germany, Investment in nuclear and renewable energy reduces $\mathrm{CO}_{2}$ 181 emissions. Moreover, the VECM method results show investment in both sectors can help reduce CO2 emissions in 182 the long-run. 
Elavarasan et al. (2020) "reviewed the drivers and barriers of renewable energy development in China, India, Iceland, Sweden, and the United States by employing SWOT analysis. This study provides a comprehensive evaluation framework based on the four major parameters: strength, weakness, opportunities, and threats for renewable energy resources. The analysis has been found that well-structured policies and abundant resources can benefit the renewable energy sector. The major factors influencing the renewable energy sectors are greater dependency on fossil fuel consumption and a multi-level government system that causes a delay in implementing policies. The other factors are lack of awareness within the country's people," absence of widespread installation of small-scale micro and Pico-hydropower, and lack of Grid captivity and transmission lines.

\section{Market regulation and $\mathrm{CO}_{2}$ emission}

192 Market regulation refers to the environmental policies used by the state administrative department to control or 193 regulate emissions using various market mechanisms. The effect of regulation on the environment has been extensively researched in different aspects. The scientific studies identified variety of economic factors, including a rapid economic growth mode, low industrial structures, and backward pollution abatement technological innovation with environmental pollution cause global warming and climate change (Zhu et al. 2014). The market based environmental regulation tools (environmental taxes) are considering to be an effective way to alleviate carbon emissions and improving environmental quality (Guo and Yuan 2020). Market based environmental regulation increases firms' cost burden, increases new constraints on firm performance, and makes firms' production and sales more difficult. The firms increase their energy efficiency and utilize their resources efficiently. This can help to control carbon emissions and improve environmental quality. In the most recent study Wang et al. (2021) also argued that government intervention and market based environmental regulation are the main mechanism for protecting environmental quality and control carbon emissions in China.

In scientific research, several studies used different methods to measure environmental regulation; the recent measures are provided (Althammer and Hille 2016; Brunel and Levinson 2016; Ren et al. 2018). Althammer and Hille (2016) provide a sector-specific indicator of climate policy stringency on multiple levels. This method is used to determine sector-specific emissions in climate policy. The study used first time a shadow price approach to environmental policy stringency for the 28 OECD countries over the time-period 1995-2009. Similarly, Brunel and Levinson (2016) evaluate the stringency of environmental regulation. They measure the environmental regulation into five broad categories and argued that each has a strength and weakness.

Ren et al. (2018) examine the impact of three types of environmental regulation on eco-efficiency across the 30 provinces in Chinese. The first is command and control-based regulation, second, market-based regulation, and third is voluntary-based environmental regulation. They found mixed results across the provinces, with market-based

214 and voluntary environmental regulations having a positive effect on eco-efficiency improvement in the eastern region,

215 while command and control environmental regulation policies have no significant impact. In the central region, on the other hand, command and control, as well as market-based environmental regulation, will foster eco-efficiency more

217 effectively than voluntary environmental regulation. Thus, these finding suggests that the effect of different types of 218 environmental regulation policies have different impact on different regions. 
Hille et al. (2020) measured environmental regulation in two dimensions: regulation design and regulation strength." In the first dimension, the authors used renewable energy goals, R\&D\&D schemes, renewable energy quotas, energy output payment or feed-in-tariff, fiscal incentive, and a carbon trading scheme. In the second dimension, the length of regulation is measured by the policy period, such as the number of years a particular policy instrument. The findings revealed that policies that promote a broader range of renewable energy technologies result in further patenting of wind and solar power-related technologies. The environmental policy instruments including $R \& D$ and research programs, targets and fiscal incentives have strong impact on reducing carbon emissions and help to improve renewable energy technologies. Ouyang et al. (2020) used generalized method of moment (GMM) estimation to investigate the factor behind $\mathrm{CO} 2$ emissions reduction in Chinese heavy industries. The findings show that industrial structure, fixed investment, and historical emissions are the primary drivers of increased sectoral emissions, while energy efficiency is a critical factor in $\mathrm{CO}_{2}$ emission reduction. Furthermore, to assess the policy results, the study used a Propensity Score Matching and Difference in Difference (PSM-DID) approach. They found that implementing an emission reduction strategy minimize $\mathrm{CO}_{2}$ emissions from heavy industries in China over sample period.

\section{Technological Innovation and $\mathrm{CO}_{2}$ emission}

234 Theoretically and empirically, the contribution of technological progress to environmental quality, especially $\mathrm{CO}_{2}$ emissions is not clear. Endogenous economic growth theory explains that an increased R\&D investment and technical capabilities can improve economic efficiency and energy resources (Aghion and Howitt 1992; Romer 1990). Many studies show that coordinating R\&D spending and technical capabilities enhances environmental quality and lowers $\mathrm{CO}_{2}$ emissions (Costantini et al. 2017; Suzuki 2015; Yang and Li 2017). Technical advancements bring innovative and more effective technological applications that can directly improve energy efficiency and reduce fossil fuel consumption. Furthermore, technological advancement helps to restructure the economy, which can help to shift the conventional factor driven model to innovation-driven economic development (Sohag et al. 2015). Thus, R\&D investment and innovation-driven based economic models promote clean energy, ultimately reducing $\mathrm{CO} 2$ emissions. However, several empirical studies test this argument and found evidence supporting technological innovation that significantly reduces CO2 emissions (Ahmed et al. 2016; Churchill et al. 2019).

Some researchers, on the other hand, conclude that $R \& D$ spending and technological progress may have a negative impact on environmental quality due to the scale effect of large-scale development, trade openness, and economic growth. As technology advances, demand for energy rises, resulting in increased pollution (Cheng et al. 2019; Kivyiro and Arminen 2014). Accordingly, "the new technologies can improve resource use efficiency, but their marginal role is diminishing, and a rapid increase in economic scale may still require more investment in natural resources." Cheng et al. (2019) investigate the impact of renewable energy and innovation on $\mathrm{CO}_{2}$ emissions for the OECD countries. The study found a positive and significant relationship between $\mathrm{CO}_{2}$ emissions and technological progress, as well as a negative relationship between renewable energy and $\mathrm{CO} 2$ emissions.

Chen and Lee (2020) examined the impact of technological innovation on $\mathrm{CO}_{2}$ emissions. This study used a

254 spatial panel data model to look at the problem from a global perspective and view the variability of technological 255 progress across countries. Overall sample estimations, they found that technical progress has no major mitigating 
impact on $\mathrm{CO}_{2}$ emissions. Sub-sample results show that technological progress can substantially reduce $\mathrm{CO}_{2}$ emissions in high-income, high-technology, and high- $\mathrm{CO}_{2}$ emission countries. Furthermore, the greater a country's degree of globalization, the more evident the impact of technological progress on $\mathrm{CO}_{2}$ emissions reduction.

To sum up, several studies used different datasets and diverse econometric methods over different periods in different regions and countries. All existing research on the effect of technological innovation, market regulation reforms and renewable energy on $\mathrm{CO}_{2}$ emissions is controversial and provides mixed outcomes. Studies indicate that developing countries' renewable energy development and technological progress are insufficient to reduce $\mathrm{CO}_{2}$ emissions. In contrast, in some developed countries, there is a strong impact on reducing $\mathrm{CO}_{2}$ emissions. At the same time, the empirical studies are limited to the developed countries. Developing countries in general, and BRICS countries in particular, have received little attention. Thus, to fill this gap and provide good supplementary to existing literature, this paper investigates the effects of renewable energy production, market policy reforms, and technological progress on carbon dioxide emissions in BRICS countries for the period 1990-2019.

\section{Data and Methodology}

\section{Data}

270 Our sample consists of "five BRICS countries, namely Brazil, Russia, India, China, and South Africa, over 19902020. The selection of time-period is based on the data availability. The data has been obtained from the database of

272 World Bank Development Indicators (World Bank, 2019) and Organization of Economic Cooperation and 273 Development (OECD) Environmental Database" (OECD, 2019)." Our main study variables are including as following Explained Variable: Carbon emissions (CE) per capita is used as core explanatory variable of our study that represents a unit of $\mathrm{CO}_{2}$ emission from primary energy combustion, such as crude oil, natural gas, coal, and other fuels, divided by the total population.

Core Explanatory Variables: Our core explanatory variables include renewable energy development, which is proxy by the contribution of renewables to total primary energy supply. The data on this variable has been taken from the OECD energy database. The second core explanatory variable of our study is market regulation, representing the measure of environmental regulation policies that the state administrative department uses to manage or limit pollution through different market mechanisms tools. To consider data quality and availability, we use environmentally related taxes to GDP as a proxy indicator for the market-based environmental regulation tool. Third core explanatory variable is technological innovation (TIN). The most research literature selects technological innovation from the input and output indicators of environmental related technologies. The input indicator of technological innovation mainly includes the investment in R\&D sector and government expenditures on environmental related technologies. The output indicator of technological innovation mainly includes the patent applications, number of patent grants and technological market value (Wang et al. 2012; Wurlod and Noailly 2018). So, this study used the output indicator of technological innovation, which is represent the "development of environment-related technologies. TIN represents creative activities; specifically, it depicts the patents which belong to environment-related technological domains, including environmental management," climate change mitigation technologies, and water resource management (Wang et al. 2012). 
Control Variables: GDP per capita (GDP), trade openness (TR) and foreign direct investment (FDI) are used as control variable. "GDP per capita measure a country's economic wealth of population. GDP per capita income is also implying the economic growth of the nation. Moreover, economic growth is widely recognized as one of the chief drivers of $\mathrm{CO}_{2}$ emission (Ren et al. 2019; Zhou et al. 2018). The current study used GDP per capita income expressed at the constant 2010 USD PPP prices. Trade openness (TR) measures the sum of exports and imports of goods and services." TR reveals the role of international trade in a nation's $\mathrm{CO}_{2}$ emissions (Hu et al. 2018; Piaggio et al. 2017). The data on TR (sum of exports and imports of goods and services \% of GDP) has been collected from the World Bank Indicator. Foreign direct investment (FDI) is another control variable of this study that measures the inward investment volume provided by non-residents of the country. FDI influence country $\mathrm{CO}_{2}$ emissions, "according to the pollution haven hypothesis, developed countries tend to transfers energy and pollution-intensive industries to developing countries with a weaker environmental regulation to save production cost." The "developing countries welcome any kind of investment from other countries which may cause serious pollution. On the other hand, according to the Halo Effect Hypothesis, the FDI may help to reduce carbon emissions (Sarkodie and Strezov 2019; Zhu et al. 2016). FDI from developed countries, in general, bring advanced technology to developing countries" and cause lowering the environmental pollution. Table 1 shows the data source, definition, and measurement of variables used in the analysis.

Table 1: Descriptive Statistics and sources

\begin{tabular}{|c|c|c|c|}
\hline Variables & Description & Units & Source \\
\hline $\mathrm{CO}_{2}$ emissions $(\mathrm{CE})$ & $\mathrm{CO}_{2}$ emissions Per Capita & Tones, Millions & OECD \\
\hline $\begin{array}{l}\text { Renewable Energy } \\
\text { Development (RED) }\end{array}$ & $\begin{array}{l}\text { The contribution of Renewable } \\
\text { energy to total energy supply } \\
\text { (excluding solid biofuels) }\end{array}$ & $\begin{array}{l}\text { Percentage of total } \\
\text { energy supply }\end{array}$ & OECD \\
\hline $\begin{array}{l}\text { Technological Innovation } \\
\text { (TIN) }\end{array}$ & $\begin{array}{l}\text { Development of environment-related } \\
\text { technologies }\end{array}$ & $\begin{array}{l}\text { Percentage of all } \\
\text { technologies }\end{array}$ & OECD \\
\hline Market Regulation (MR) & Environmentally related taxes & Percentage of GDP & OECD \\
\hline GDP per capita (GDPP) & Real GDP per capita & US Dollar, 2015 & WDI \\
\hline Trade Openness (TR) & $\begin{array}{l}\text { sum of exports and imports of goods } \\
\text { and services }\end{array}$ & Percentage of GDP & WDI \\
\hline Foreign direct investment (FDI) & $\begin{array}{l}\text { Foreign direct investment, net } \\
\text { inflows }\end{array}$ & Percentage of GDP & WDI \\
\hline
\end{tabular}

Theoretical Framework and Model Construction

311 Theoretically, the relationship between renewable energy development, technological innovation and carbon dioxide 312 emission gain an importance in the field of ecological economics, innovation and development, environment and 313 sustainability. The carbon emissions relation linked with various factors like country level of income, renewable 314 energy consumption, economic growth, fossil fuel energy consumption, regulation policies and financial development 315 etc. The several factors provide different pathways either negative or positive to carbon emissions. Moreover, the 
theoretical linkages between carbon emissions, renewable energy, technological innovation and market regulation are straightforward. The more utilization of renewable energy resources lowering the demand for fossil fuel energy and carbon emissions (Doğan et al. 2021; Dogan and Seker 2016).

On the other hand, the market based environmental regulation policies significantly promote technological innovation and reduce environmental "pollution in the process of industrial transformation. The environmental regulation policies force to improving energy efficiency and reduced undesired output such as carbon dioxide emissions (Du et al. 2021). Similarly, technological innovation promotes the maturity of technological" production, industrial structure and development of new products as a result its improve the industrial ecological chain (Yang et al. 2020). The study used two-step econometric model and nonlinear mediating effect model. Based on this study we construct the following theoretical model. Accordingly, environmental regulation effect the carbon emissions directly and indirectly. The regulation promote energy efficiency directly and indirectly helps to improve the energy efficiency through the technological innovation.

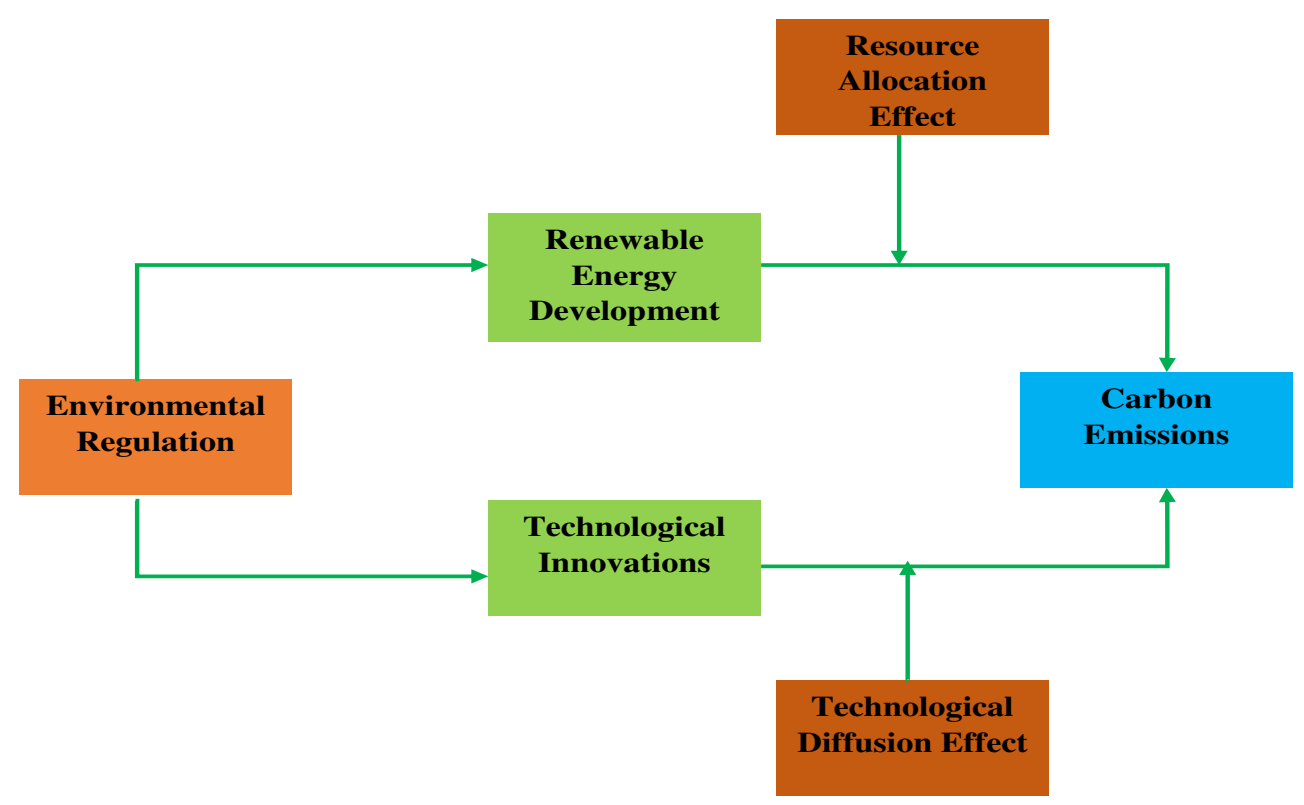

\section{Figure: Theoretical Framework}

This study investigates the impact of renewable energy development, market regulation, and technological innovation on carbon emissions over the period 1990 to 2019 in a panel of 5 BRICS countries. First, the following benchmark model is set to test the relationship among variables.

$$
C E_{i t}=\beta_{o}+\beta_{1} R E D_{i t}+\beta_{2} \operatorname{TIN}_{i t}+\beta_{3} M R_{i t}+\Sigma \beta_{4} X_{i t}+\mu_{i}+\omega_{t}+\varepsilon_{i t} \ldots \ldots \text {. (1) }
$$

Where $i$ and $t$ denotes country and year respectively. $C E_{i t}$ denotes the dependent variable carbon emissions per capita, $R E D_{i t}$ is renewable energy development, $T I N_{i t}$ is technological development and $M R_{i t}$ is market regulation. $X_{i t}$ represents the set of control variables such as GDP per capita (GDPP), trade openness (TR) and foreign direct investment, net inflows (FDI). $\mu_{i}$ represents unobserved country individual effects, $\omega_{t}$ is time effects and $\varepsilon_{i t}$ is random error term. 
The existing literature (Yang et al. 2020) shows that market regulation policies have directly and indirectly effect the carbon emissions, technological innovations and renewable energy development. In this regard, we check the role of market based environmental policies, the interaction terms $M R_{i t} \times R E D_{i t}$ and $M R_{i t} \times T I N_{i t}$ are added in model (1), respectively.

$$
\begin{gathered}
C E_{i t}=\beta_{o}+\beta_{1} R E D_{i t}+\beta_{2} T I N_{i t}+\beta_{3} M R_{i t}+\beta_{4}\left(M R_{i t} \times R E D_{i t}\right)+\beta_{5}\left(M R_{i t} \times T I N_{i t}\right)+\Sigma \beta_{6} X_{i t}+\mu_{i}+\omega_{t} \\
+\varepsilon_{i t} \ldots \ldots . .(2)
\end{gathered}
$$

Finally, in order to explore the linear and nonlinear relationship, the panel nonlinear autoregressive distributed lag model (NARDL) is employed to estimate symmetric and asymmetric relationship among study variables. This methodology has several advantages over the traditional approaches. First, this approach can be used for both order of integration, whether regressors are purely I (1), I (0) or mutually integrated order of integration (Pesaran and Shin 1996; Pesaran et al. 2001). Second, this approach make estimation possible even though variables are found to be endogenous (Pesaran and Shin 1996; Pesaran et al. 2001). Third, the ARDL approach provide both short and long run effects of independent variables on dependent variable simultaneously. Because of these advantages, we estimate the following nonlinear models.

$$
\begin{gathered}
C E_{i t}=\beta_{o}+\beta_{1} R E D_{i t}^{+}+\beta_{2} R E D_{i t}^{-}+\beta_{3} \operatorname{TIN}_{i t}^{+}+\beta_{4} T I N_{i t}^{-}+\beta_{5} M R_{i t}^{+}+\beta_{6} M R_{i t}^{-}+\beta_{7} M R \times R E D_{i t}^{+}+\beta_{8} M R \times R E D_{i t}^{-} \\
+\beta_{9} M R \times T I N_{i t}^{+}+\beta_{10} M R \times T I N_{i t}^{-}+\Sigma \beta_{11} X_{i t}+\mu_{i}+\omega_{t}+\varepsilon_{i t} \ldots \ldots . .(3)
\end{gathered}
$$

Equation (3) shows the nonlinear asymmetric relationship, response of positive and negative changes in renewable energy development $\left(R E D_{i t}\right)$, technological development $\left(T I N_{i t}\right)$, market regulation $\left(M R_{i t}\right)$ and their interaction terms to carbon emissions $\left(C E_{i t}\right)$, respectlviey. While equation (1) and (2) assumed the linear relationship among the variables.

$R E D_{i t}^{+}=\sum_{i=1}^{t} \Delta R E D_{i}^{+}=\sum_{i=1}^{t} \max \left(\Delta R E D_{i}, 0\right)$

$$
R E D_{i t}^{-}=\sum_{i=1}^{t} \Delta R E D_{i}^{-}=\sum_{i=1}^{t} \min \left(\Delta R E D_{i}, 0\right)
$$$$
\operatorname{TIN}_{i t}^{+}=\sum_{i=1}^{t} \Delta \operatorname{TIN}_{i}^{+}=\sum_{i=1}^{t} \max \left(\Delta \operatorname{TIN}_{i}, 0\right)
$$$$
\operatorname{TIN}_{i t}^{-}=\sum_{i=1}^{t} \Delta \operatorname{TIN}_{i}^{-}=\sum_{i=1}^{t} \min \left(\Delta \operatorname{TIN}_{i}, 0\right)
$$$$
M R_{i t}^{+}=\sum_{i=1}^{t} \Delta M R_{i}^{+}=\sum_{i=1}^{t} \max \left(\Delta M R_{i}, 0\right)
$$$$
M R_{i t}^{-}=\sum_{i=1}^{t} \Delta M R_{i}^{-}=\sum_{i=1}^{t} \min \left(\Delta M R_{i}, 0\right)
$$

$$
M R \times R E D_{i t}^{+}=\sum_{i=1}^{t} \Delta M R \times R E D_{i}^{+}=\sum_{i=1}^{t} \max \left(\Delta M R \times R E D_{i}, 0\right)
$$




$$
\begin{aligned}
& M R \times R E D_{i t}^{-}=\sum_{i=1}^{t} \Delta M R \times R E D_{i}^{-}=\sum_{i=1}^{t} \min \left(\Delta M R \times R E D_{i}, 0\right) \\
& M R \times T_{I I}^{+}=\sum_{i=1}^{t} \Delta M R \times T_{I}^{+}=\sum_{i=1}^{t} \max \left(\Delta M R \times T I N_{i}, 0\right) \ldots \\
& M R \times T_{I I N_{i t}^{-}}=\sum_{i=1}^{t} \Delta M R \times T I N_{i}^{-}=\sum_{i=1}^{t} \min \left(\Delta M R \times T I N_{i}, 0\right) \ldots
\end{aligned}
$$

\section{Econometric Methodology}

This study used standard econometric methodology, our analysis starts with the testing cross-sectional dependency, panel unit root test, cointegration, linear and nonlinear ARDL, respectively.

\section{Cross sectional Dependency}

373 The "first step toward the empirical analysis is to test the existence of cross-section dependency (CD) across the countries." To examine the cross-section dependency, this study conduct parametric test suggested by Pesaran (2004). The test is better power properties and can be used with both balance and unbalance panels. The test has also good properties for both small cross-section and time series dimensions (Pesaran 2004). The CD test is robust to parameter heterogeneity and structural breaks, and does not required a priori specification. The test is applicable for the wide range of panel data models." The null hypothesis of "test is no cross section dependence;" $H_{0}: \operatorname{Cov}\left(\varepsilon_{i t}, \varepsilon_{j t}\right)=0$ for all $\mathrm{t}$, and $\mathrm{i} \neq \mathrm{j}$ is tested against alternative hypothesis of $H_{1}: \operatorname{Cov}\left(\varepsilon_{i t}, \varepsilon_{j t}\right) \neq 0$ for at least one pair of $\mathrm{i} \neq \mathrm{j}$. Pesaran (2004) developed CD test statistics as follows;

$$
C D=\sqrt{\frac{2 T}{N(N-1)} \sum_{i-1}^{N-1} \sum_{j=i+1}^{N} \hat{\rho}_{i j} \ldots \ldots \ldots}
$$

Where $\hat{\rho}_{i j}$ is the estimates "of pairwise correlation of residuals from the OLS estimates of Eq. (1) for each i."

$$
\hat{\rho}_{\mathrm{ij}}=\hat{\rho}_{\mathrm{ji}}=\frac{\sum_{\mathrm{t}=1}^{\mathrm{T}} \hat{\varepsilon}_{\mathrm{it}} \hat{\varepsilon}_{\mathrm{jt}}}{\left(\sum_{\mathrm{t}=1}^{\mathrm{T}} \hat{\varepsilon}_{\mathrm{it}}{ }^{2}\right)^{1 / 2}\left(\sum_{\mathrm{t}=1}^{\mathrm{T}} \hat{\varepsilon}_{\mathrm{jt}}{ }^{2}\right)^{1 / 2}} \cdots \cdots
$$

Where $\widehat{\varepsilon}_{\text {it }}$ is OLS estimates of $\varepsilon_{\text {it }}$ in Eq. (1). The results of CD test are reported in Table 3.

\section{Panel Unit Root Test}

In the panel data framework two generation of test are used. In the "first generation, panel unit root test assumes that the cross sectional unites are cross- sectional independent. While, the second generation unit root test relax" the assumption of cross-sectional independent and it allows the cross-sectional dependency "among the cross-sectional units. This study used the second generation panel unit root test, namely, Maddala and Wu (1999) test (WU) and Pesaran (2007) panel unit (CIPS) root" test to determining the degree of integration of each variable. The advantage of these tests are that it allows for the cross section dependency. "The test statistics developed by Pesaran (2007) can be written as following. 


\section{Linear and Nonlinear Panel Cointegration Tests}

395 After determining the order of integration, the next step will be to look into the possibility of a long-term relationship between variables. To test the presence of long-run relationship among variables this study used both linear and nonlinear panel cointegration tests. In the first step, we apply Westerlund (2007) panel cointegration test. The test allows to cross sectional dependency. Westerlund (2007) test include four statistics, two for group mean statistics and two for the panel statistics. The null hypothesis of test statics is no cointegration, while alternative hypothesis is at least one individual unit of panel is cointegrated. The test statistics is written as following.

$$
\begin{aligned}
& G_{t}=N^{-1} \sum_{i=1}^{N} \frac{\dot{\psi}}{\operatorname{Se}(\dot{\psi})} \ldots \ldots \ldots \ldots \ldots \ldots \\
& \mathrm{G}_{\mathrm{a}}=\mathrm{N}^{-1} \sum_{\mathrm{i}-1}^{\mathrm{N}} \frac{\mathrm{T} \dot{\psi}}{\psi^{\prime}(1)} \\
& \mathrm{P}_{\mathrm{T}}=\frac{\dot{\psi}}{\operatorname{Se}(\dot{\psi})} \ldots
\end{aligned}
$$$$
\mathrm{P}_{\mathrm{a}}=\mathrm{T} \Psi
$$

Where $G_{t}$ and $G_{a}$ represent the group mean statistics, while $P_{T}$ and $P_{a}$ represent panel statistics.

In the second step, we conduct the nonlinear panel cointegration test proposed by Hatemi-J (2020). This test detects the eventual hidden cointegration relationship between positive and negative component of variables. This study follows the method of Altıntaş and Kassouri (2020), we consider multi version of cointegration analysis by allowing the control variables. It is assuming that control variables are enter symmetrically in the cointegration relations. Considering the following potential cointegration model.

$$
\begin{aligned}
& y_{i t}^{+}=\gamma_{i}^{+}+\varphi_{i}^{+} Z_{i t}^{+}+X_{i t}+\eta_{i}^{+} \\
& y_{i t}^{-}=\gamma_{i}^{-}+\varphi_{i}^{-} Z_{i t}^{-}+X_{i t}+\eta_{i}^{-}
\end{aligned}
$$

413 Where $y_{i t}^{+}$and $y_{i t}^{-}$denotes the positive and negative partial cumulative of carbon emissions, respectively. $Z_{i t}^{+}$and $Z_{i t}^{-}$

414 represent positive and negative partial integers of our core explanatory variables, respectively. $X_{i t}$ are control variables

415 of our study. We test the hypothesis; $\left[y_{i t}^{+} ; Z_{i t}^{+}\right]$are cointegrated in the panel if $\eta_{i}^{+}$is stationary, $\left[y_{i t}^{-} ; Z_{i t}^{-}\right]$are cointegrated in the panel if $\eta_{i}^{-}$is stationary, $\left[y_{i t}^{+} ; Z_{i t}^{-}\right]$are cointegrated in the panel if $\eta_{i}^{+}$is stationary and $\left[y_{i t}^{-} ; Z_{i t}^{+}\right]$are cointegrated in the panel if $\eta_{i}^{-}$is stationary. The cross- sectional Dickey Fuller (CDF) test is used for testing the 418 cointegration relations.

\section{Linear and Nonlinear ARDL}

420 In the panel data framework, mean group (MG) and pooled mean group (PMG) model was developed by Pesaran and 421 Smith (1995) and Pesaran et al. (1999) to estimate the linear and nonlinear relationship among the variables. In this 422 study, we follow the method of Pesaran et al. (1999) and developed the following linear dynamic heterogeneous panel 423 ARDL model. 


$$
\Delta C E_{i t}=\zeta_{i 1} C E_{i t-1}+\psi_{i 2} R E D_{i t-1}+\psi_{i 3} T I N_{i t-1}+\psi_{i 4} M R_{i t-1}+\psi_{i 5}(M R \times R E D)_{i t-1}+\psi_{i 6}(M R \times T I N)_{i t-1}
$$$$
+\psi_{i 7} X_{i t-1}+\sum_{j=1}^{m} \beta_{1 i j} \Delta C E_{i t-j}+\sum_{j=0}^{m}\left(\beta_{2 i j} \Delta R E D_{i t-j}+\beta_{3 i j} \Delta T I N_{i t-j}+\beta_{4 i j} \Delta M R_{i t-j}+\beta_{5 i j} \Delta M R\right.
$$

$$
\left.\times R E \mathrm{D}_{i t-j}+\beta_{6 i j} \Delta M R \times T I N_{i t-j}+\beta_{7 i j} \Delta X_{i t-j}\right)+\mu_{i}+\omega_{t}+\varepsilon_{i}
$$

Where $\psi_{i}$ and $\beta_{i j}$ denotes the long-run and short-run coefficients. $m$ represent the optimal lag length and $\Delta$ is first difference. $\mu_{i}$ and $\omega_{t}$ shows the group specific effect and time effect. Equation (25) contain two parts, the first part of the equation represents long run relationship among the variables and second part represent error correction dynamics.

The long-run coefficients are computed as $-\frac{\psi_{i j}}{\zeta_{i 1}}$. The error correction mechanism is $v_{i t-1}=\alpha_{1 i}-\psi_{i}\left(C E_{i t-1}+\right.$ $R E D_{i t-1}+T_{I N_{i t-1}}+M R_{i t-1}+M R \times R E D_{i t-1}+M R \times T I N_{i t-1}+$ Control $\left._{i t-1}\right)$. This represent the speed of adjustment term. The linear type of error correction model can be written as following.

$$
\begin{aligned}
\Delta C E_{i t}=\Gamma_{1} v_{i t-1} & +\sum_{j=1}^{m} \beta_{1 i j} \Delta C E_{i t-j}+\sum_{j=1}^{m} \beta_{2 i j} X_{i t-1}+\sum_{j=0}^{m}\left(\beta_{2 i j} \Delta R E D_{i t-j}+\beta_{3 i j} \Delta T I N_{i t-j}+\beta_{4 i j} \Delta M R_{i t-j}\right. \\
& \left.+\beta_{5 i j} \Delta M R \times R E D_{i t-j}+\beta_{6 i j} \Delta M R \times T I N_{i t-j}+\beta_{7 i j} \Delta X_{i t-j}\right)+\mu_{i}+\omega_{t}+\varepsilon_{i t} \ldots \ldots \ldots(26)
\end{aligned}
$$

Under the nonlinear scenario of the panel ARDL, known as asymmetric ARDL, one assumed that positive and negative shocks in the regression mode. We implement the Pesaran and Smith (1995) method and consider the following asymmetric version of equation.

$$
\begin{aligned}
\Delta C E_{i t}=\omega_{i j 1} C E_{i t-1} & +\psi_{i j 2} R E D_{i t-1}^{+}+\psi_{i j 3} R E D_{i t-1}^{-}+\psi_{i j 4} T I N_{i t-1}^{+}+\psi_{i j 5} T I N_{i t-1}^{-}+\psi_{i j 6} M R_{i t-1}^{+}+\psi_{i j 7} M R_{i t-1}^{-} \\
& +\psi_{i j 8} M R \times R E D_{i t-1}^{+}+\psi_{i j 9} M R \times R E D_{i t-1}^{-}+\psi_{i j 10} M R \times T I N_{i t-1}^{+}+\psi_{i j 11} M R \times T I N_{i t-1}^{-} \\
& +\pi_{i j 12} X_{i t-j}+\sum_{j=1}^{m} \pi_{1 i j} \Delta C E_{i t-j}+\sum_{j=0}^{m}\left(\varphi_{2 i j} \Delta R E D_{i t-j}^{+}+\varphi_{i j 3} \Delta R E D_{i t-j}^{-}+\varphi_{i j 4} \Delta T I N_{i t-j}^{+}\right. \\
& +\varphi_{i j 5} \Delta T I N_{i t-j}^{-}+\varphi_{i j 6} \Delta M R_{i t-j}^{+}+\varphi_{i j 7} \Delta M R_{i t-j}^{-}+\varphi_{i j 8} \Delta M R \times R E D_{i t-j}^{+}+\varphi_{i j 9} \Delta M R \times R E D_{i t-j}^{-} \\
& \left.+\varphi_{i j 10} \Delta M R \times T I N_{i t-j}^{+}+\varphi_{i j 11} \Delta M R \times T I N_{i t-j}^{-}+\varphi_{i j 12} \Delta X_{i t-j}\right)+\mu_{i}+\omega_{t}+\varepsilon_{i t} \cdots \cdots \cdots(27)
\end{aligned}
$$

Equation (27) shows the asymmetric relationship among variables of study in the short and long-run. The long-run coefficient are computed as $-\frac{\psi_{i j s}{ }^{+}}{\omega_{i j 1}}$ and $-\frac{\psi_{i j s}{ }^{-}}{\omega_{i j 1}}$. The non- linear version of error correction model can be further simplified as following.

$$
\begin{aligned}
\Delta C E_{i t}=\Gamma_{2} v_{i t-1} & +\omega_{i j 2} X_{i t-j}+\sum_{j=1}^{m} \pi_{1 i j} \Delta C E_{i t-j}+\sum_{j=0}^{m}\left(\varphi_{2 i j} \Delta R E D_{i t-j}^{+}+\varphi_{i j 3} \Delta R E D_{i t-j}^{-}+\varphi_{i j 4} \Delta T I N_{i t-j}^{+}\right. \\
& +\varphi_{i j 5} \Delta T I N_{i t-j}^{-}+\varphi_{i j 6} \Delta M R_{i t-j}^{+}+\varphi_{i j 7} \Delta M R_{i t-j}^{-}+\varphi_{i j 8} \Delta M R \times R E D_{i t-j}^{+}+\varphi_{i j 9} \Delta M R \times R E D_{i t-j}^{-} \\
& \left.+\varphi_{i j 10} \Delta M R \times T I N_{i t-j}^{+}+\varphi_{i j 11} \Delta M R \times T I N_{i t-j}^{-}+\varphi_{i j 12} \Delta X_{i t-j}\right)+\mu_{i}+\omega_{t}+\varepsilon_{i t} \ldots \ldots \ldots(28)
\end{aligned}
$$

Where $v_{i t-1}$ represent asymmetric error term, capture the long-run equilibrium in equation. $\Gamma_{2}$ represent the speed of 


\section{$451 \quad$ Empirical Results}

\section{Univariate Analysis}

453 Table 2 reports descriptive statistics of dataset including mean, standard deviation, minimum and maximum values,

454 of $\mathrm{CO}_{2}$ emissions (CE), renewable energy development (RED), technological innovation (TIN), market regulation

455 (MR), GDP per capita (GDPP), trade openness (TR) and foreign direct investment (FDI) over the sample period 1990-

$4562020 "$.

457 Table 2: Descriptive Statistics and sources

\begin{tabular}{lcccc}
\hline \multicolumn{1}{c}{ Variables } & Mean & Std. Dev. & Min & Max \\
\hline $\mathrm{CO}_{2}$ emissions (CE) & 6.902 & 1.095 & 5.217 & 9.219 \\
Renewable Energy Development (RED) & 5.062 & 6.517 & .014 & 22.745 \\
Technological Innovation (TIN) & 2.102 & .364 & 1.163 & 2.76 \\
Market Regulation (MR) & 1.268 & .583 & .169 & 2.756 \\
GDP per capita (GDPP) & 9.045 & .766 & 7.25 & 10.164 \\
Trade Openness (TR) & 3.653 & .408 & 2.719 & 4.706 \\
Foreign direct investment (FDI) & 2.032 & 1.496 & -.066 & 6.187 \\
\hline
\end{tabular}

458

459 The correlation between variables are reported in Table 3. The first column shows the correlation between carbon

460 emissions (CE) and other variables of study. The results revealed that negative and significant correlation $(\mathrm{r}=-0.379 *)$

461 between CE and renewable energy development (RED). Technological innovation (TIN) is also negative related with

$462 \mathrm{CE}$ but it is statistically insignificant $(\mathrm{r}=-0.032)$. Market based environmental regulation is negative and statistically

463 significant with CE ( $\left.\mathrm{r}=-0.166^{*}\right)$. This implies that imposition of taxes on production activities decrease the carbon

464 emissions. Trade openness (TR) and foreign direct investment (FDI) are statistically significant and positively

465 correlated with CE. This indicates that inflow of foreign direct investment and sum of exports and imports increase

466 the carbon emissions.

467

Table 3: Pairwise Correlation Matrix

\begin{tabular}{llllllll}
\hline Variables & $\mathbf{( 1 )}$ & $\mathbf{( 2 )}$ & $\mathbf{( 3 )}$ & $\mathbf{( 4 )}$ & $\mathbf{( 5 )}$ & $\mathbf{( 6 )}$ & $\mathbf{( 7 )}$ \\
\hline (1) Carbon Emission (CE) & 1.000 & & & & & & \\
(2) Renewable Energy Development (RED) & $-0.379^{*}$ & 1.000 & & & & & \\
(3) Technological Innovation (TIN) & -0.032 & -0.059 & 1.000 & & & & \\
(4) Market Regulation (MR) & $-0.166^{*}$ & $-0.537 *$ & $0.323^{*}$ & 1.000 & & & \\
(5) GDP Per Capita (GDPP) & -0.132 & $0.273^{*}$ & $0.246^{*}$ & $0.358^{*}$ & 1.000 & & \\
(6) Trade Openness (TR) & $0.346^{*}$ & $-0.640^{*}$ & $0.280^{*}$ & $0.604^{*}$ & $0.316^{*}$ & 1.000 & \\
(7) Foreign Direct Investment (FDI) & $0.258^{*}$ & $0.252^{*}$ & 0.050 & $-0.345^{*}$ & 0.025 & 0.041 & 1.000 \\
\hline \multicolumn{2}{c}{ Note: $* * * p<0.01, * * p<0.05, * p<0.1$} & & & & &
\end{tabular}




\section{Cross sectional Dependency and Panel Unit root test results}

470 We begin formal analysis by testing the cross sectional dependency. In doing this, we apply Breusch-Pagan LM,

471 Pesaran scaled LM, Bias corrected scaled LM and Pesaran CD test as shown in Table 4. The findings show that the

472 strength and cross sectional dependency among the sample countries. The null hypothesis of no cross-sectional

473 dependency presented by the test statistics is rejected at a high statistical significance level for all variables. As a

474 result, we adopt the alternative hypothesis of panel country cross-sectional dependency.

475 Table 4: Cross- sectional dependency (CD) test

\begin{tabular}{|c|c|c|c|c|}
\hline Variables & Breusch-Pagan LM & Pesaran scaled LM & Bias corrected scaled LM & Pesaran CD \\
\hline Carbon Emission (CE) & $189.662 * * *$ & $39.056 * * *$ & $38.972 * * *$ & $7.492 * * *$ \\
\hline Renewable Energy & $117.772 * * *$ & $22.981 * * *$ & $22.897 * * *$ & $8.338 * * *$ \\
\hline \multicolumn{5}{|l|}{ Development (RED) } \\
\hline Tech. Innovation (TIN) & $15.988 * * *$ & 0.221 & 0.138 & $2.371 * * *$ \\
\hline Market Regulation (MR) & $49.739 * * *$ & $7.768 * * *$ & $7.685 * * *$ & $2.193 * * *$ \\
\hline GDP Per Capita (GDPP) & $257.209 * * *$ & $54.159 * * *$ & $54.076 * * *$ & $16.002 * * *$ \\
\hline Trade Openness (TR) & $106.180 * * *$ & $20.388 * * *$ & $20.305 * * *$ & $8.005 * * *$ \\
\hline Foreign Direct & $43.666 * * *$ & $6.410 * * *$ & $6.327 * * *$ & $3.881 * * *$ \\
\hline Investment (FDI) & & & & \\
\hline
\end{tabular}

Note: *** denotes the rejection of null hypothesis of cross-sectional independency

477 Table 5 reports the second generation panel unit root test. We check the stochastic properties of panel data. We used

478 Maddala and Wu (1999) test and Pesaran (2007) panel unit root test and allow the cross sectional dependency among

479 the panel countries. The tests are done for both constant and constant and trend. The optimal lag length selected based

480 on the Akaike information criteria (AIC). It is clear that both test statistics does not reject the null hypothesis of unit

481 root with constant and constant and trend at level for all variables as shown in table 5. Thus, it is concluded that a

482 panel unit root is present in the level series with intercept and constant. This indicates that the variables under study

483 are integrated of order I (1).

484 Table 5: Panel unit root test Results

\begin{tabular}{lccccc}
\hline \multirow{2}{*}{ Variables } & \multicolumn{3}{c}{ Maddala and Wu } & \multicolumn{3}{c}{ Pesaran CIPS } \\
\cline { 2 - 6 } & Lags & Constant & Constant and trend & Constant & Constant and trend \\
\hline CE & 0 & 15.557 & 3.006 & -1.060 & 2.020 \\
& 1 & $20.510^{* * *}$ & 11.240 & $-2.426^{* * * *}$ & 0.490 \\
& 2 & 16.004 & 12.824 & $-3.459^{* * *}$ & -1.037 \\
\multirow{2}{*}{ RED } & 3 & 13.927 & $17.357^{*}$ & $-4.495^{* * * *}$ & $-2.545^{* * *}$ \\
& 0 & 10.913 & 5.777 & 2.087 & 2.458 \\
& 1 & 15.558 & 9.237 & 1.108 & 1.726 \\
& 2 & 14.997 & 11.363 & 1.670 & 2.740 \\
& 3 & 14.885 & $17.362^{* *}$ & 0.986 & 1.692 \\
\hline
\end{tabular}




\begin{tabular}{|c|c|c|c|c|c|}
\hline \multirow[t]{4}{*}{ TIN } & 0 & $20.521 * * *$ & 14.267 & $-2.565^{* * *}$ & $-3.827 * * *$ \\
\hline & 1 & $16.834 * * *$ & 10.786 & $-1.463 * * *$ & $-2.857 * * *$ \\
\hline & 2 & 7.441 & 2.280 & 0.723 & -0.283 \\
\hline & 3 & 6.359 & 2.621 & 1.440 & 1.344 \\
\hline \multirow[t]{4}{*}{ MR } & 0 & 9.532 & 4.867 & 1.138 & 1.028 \\
\hline & 1 & 13.790 & 6.030 & 0.744 & 0.874 \\
\hline & 2 & $20.104 * * *$ & 9.710 & 0.189 & 0.028 \\
\hline & 3 & 12.498 & 5.840 & -0.051 & -0.356 \\
\hline \multirow[t]{4}{*}{ GDPP } & 0 & 11.140 & 12.488 & -1.138 & 1.562 \\
\hline & 1 & 6.457 & 10.307 & $-4.314 * * *$ & $-3.610 * * *$ \\
\hline & 2 & 4.789 & 5.121 & $-2.639 * * *$ & $-4.610 * * *$ \\
\hline & 3 & 6.035 & 4.467 & -1.116 & $-2.721 * * *$ \\
\hline \multirow[t]{4}{*}{ TR } & 0 & $30.211 * * *$ & $1.125 * * *$ & $-2.323 * * *$ & $-1.334 *$ \\
\hline & 1 & $41.837 * * *$ & $8.152 * * *$ & $-3.543 * * *$ & $-3.426 * * *$ \\
\hline & 2 & 10.835 & 4.527 & $-1.681 * * *$ & $-1.963 * * *$ \\
\hline & 3 & 9.783 & 9.043 & $-1.763 * * *$ & $-3.552 * * *$ \\
\hline \multirow[t]{4}{*}{ FDI } & 0 & $29.445 * * *$ & $6.234 * * *$ & $-1.810^{* * *}$ & $-1.766^{* * *}$ \\
\hline & 1 & $21.493 * * *$ & $7.870 * * *$ & -1.221 & $-1.965 * * *$ \\
\hline & 2 & $17.327 * *$ & $7.166^{* * * *}$ & -1.132 & $-2.411 * * *$ \\
\hline & 3 & 12.890 & 8.099 & 1.503 & 0.541 \\
\hline
\end{tabular}

Linear and Nonlinear Panel Cointegration Tests Results

487 After testing the stochastic property of data, the next step is to check the cointegration among the study variables. We used Westerlund (2007) test for linear cointegration and Hatemi-J (2020) test for asymmetric relationship among the ascending and descending component of study variables as shown in Table 6 . The overall findings suggest that carbon emissions, renewable energy development, market regulation, and technical innovation are all linked through symmetric and asymmetric cointegrating vectors. this supports the presence of long-run symmetric and asymmetric stable relationships among the variables over the sample period 1990-2020.

Table 6: Linear and Nonlinear Co-Integration Test Results

\begin{tabular}{cccccr}
\hline & Linear Co-Integration Test & \multicolumn{3}{c}{ Nonlinear Co-Integration Test } \\
\hline & Stat & p-value & $\mathbf{H}_{\mathbf{0}} \mathbf{\text { I }}(\mathbf{1}) \mathbf{\text { vs H}} \mathbf{H}_{\mathbf{1}} \mathbf{I} \mathbf{\mathbf { ( } ( \mathbf { 0 } )}$ & Stat & p-value \\
\hline $\mathrm{G}_{\mathrm{t}}$ & -1.766 & 0.926 & {$\left[y_{i t}^{+} ; Z_{i t}^{+}\right]$} & -4.676 & $0.000^{\mathrm{a}}$ \\
$\mathrm{G}_{\mathrm{a}}$ & $-5.519^{\mathrm{c}}$ & 0.067 & {$\left[y_{i t}^{+} ; Z_{i t}^{-}\right]$} & -2.826 & $0.010^{\mathrm{c}}$ \\
$\mathrm{P}_{\mathrm{T}}$ & $-4.621^{\mathrm{b}}$ & 0.023 & {$\left[y_{i t}^{-} ; Z_{i t}^{-}\right]$} & -3.397 & $0.000^{\mathrm{a}}$ \\
$\mathrm{P}_{\mathrm{a}}$ & $-6.891^{\mathrm{a}}$ & 0.000 & {$\left[y_{i t}^{-} ; Z_{i t}^{+}\right]$} & -4.434 & $0.000^{\mathrm{a}}$
\end{tabular}

494 Note: ${ }^{\text {a, b, c }}$ denotes statistical significant at 1,5 and $10 \%$, respectively. We set the maximum lags/ led length 1 by 495 including constant and trend. The lags are selected based on the AIC 


\section{Linear and Nonlinear ARDL Results}

497 We estimated the short and long run symmetric and asymmetric relationships using the mean group and pooled mean 498 group estimation methods after determining the presence of symmetric and asymmetric cointegration relationships 499 between research variables as shown in Table $7 \& 8$.

$500 \quad$ Table 7: Linear ARDL Results

\begin{tabular}{lclllll}
\hline \multirow{2}{*}{ Variables } & \multicolumn{2}{c}{ Mean Group Estimates } & \multicolumn{5}{c}{ Pooled Mean Group Estimates } \\
\cline { 2 - 7 } Coefficients & Standard Err. & Prob. & Coefficients & Standard Err. & Prob. \\
\hline Panel A: Long Run Estimates & & & & \\
RED & -0.398 & 0.201 & $(0.001)^{*}$ & -0.312 & 0.026 & $(0.008)^{* * *}$ \\
TIN & -0.832 & 0.386 & $(0.000)^{* * *}$ & -0.314 & 0.118 & $(0.006)^{* * *}$ \\
MR & -0.914 & 0.288 & $(0.007)^{* *}$ & -0.226 & 0.041 & $(0.001)^{* * *}$ \\
MR_RED & -1.287 & 0.102 & $(0.000)^{* * *}$ & -1.032 & 0.019 & $(0.010)^{* * *}$ \\
MR_TIN & -1.441 & 0.287 & $(0.000)^{* * *}$ & -1.123 & 0.017 & $(0.000)^{* * *}$ \\
GDPP & 0.203 & 0.101 & $(0.009)^{* * *}$ & 0.116 & 0.012 & $(0.007)^{* * *}$ \\
TR & 1.890 & 0.206 & $(0.000)^{* * *}$ & 0.002 & 0.013 & $(0.881)$ \\
FDI & 0.034 & 0.053 & $(0.520)$ & 0.012 & 0.012 & $(0.853)$ \\
\hline Panel B: Short Run Estimates & & & & & \\
\hline$\Delta$ RED & -0.856 & 0.454 & $(0.005)^{*}$ & -0.629 & 0.336 & $(0.065)^{* *}$ \\
$\Delta$ TIN & 0.145 & 0.122 & $(0.713)$ & -0.381 & 0.083 & $(0.001)^{* * *}$ \\
$\Delta$ MR & -0.545 & 0.206 & $(0.035)^{* *}$ & -0.726 & 0.288 & $(0.003)^{* * *}$ \\
$\Delta$ MR_RED & -1.404 & 0.984 & $(0.154)$ & -1.292 & 0.167 & $(0.010)^{* * *}$ \\
$\Delta$ MR_TIN & -1.086 & 1.101 & $(0.393)$ & -1.274 & 0.064 & $(0.000)^{* * *}$ \\
$\Delta$ GDPP & 0.700 & 0.255 & $(0.006)^{* * *}$ & 0.448 & 0.075 & $(0.000)^{* * *}$ \\
$\Delta$ TR & 0.095 & 0.047 & $(0.009)^{* * *}$ & 0.079 & 0.019 & $(0.000)^{* * *}$ \\
$\Delta$ FDI & -0.004 & 0.006 & $(0.540)$ & -0.175 & 0.012 & $(0.000)^{* * *}$ \\
ECT & -0.956 & 0.454 & $(0.005)^{* *}$ & -0.996 & 0.050 & $(0.000)^{* * *}$ \\
\hline Panel C: Diagnostic Statistics & & & & & \\
\hline Hausman Test & & & & 2.94 & & \\
\hline & & & & $(0.417)$ & & \\
\hline & & & & & \\
\hline
\end{tabular}

Panel A of Table 7 shows linear/ symmetric short and long run results which indicates that renewable energy development (RED) is negative significant impact on carbon emissions (CE). This implies that $1 \%$ increase in renewable energy consumption, the carbon emissions will decrease by $-0.3 \%$. The coefficient of technological innovation (TIN) is also significant negative with CE, this implies that more efficient and cleaner green technology help to reduce carbon emissions. $1 \%$ increase in green innovation carbon emission will decrease by -0.31 to $-0.83 \%$ respectively. This indicates that environmental related technologies are the key to improve environment and energy efficiency. These findings consistent with most recent study (Chen and Lee 2020). Meanwhile, environmental 


\section{3}

regulation has direct and indirect significant negative impact on CE. $1 \%$ increase taxes related to environmental pollution, the carbon emissions decreased by $-0.22 \%$ to $-0.91 \%$, respectively. This shows that the government policies regarding the limiting of environmental pollution i.e. market based regulation support to the environmental performance and enforced to control emission pollution in study sample countries. The market based regulation also play significant mediating role between technological invocation and $\mathrm{CE}$, and renewable energy development and CE. The findings support that the environmental regulation is more conducive to environmental quality, promoting green technological innovations and renewable energy consumption. Our findings are more consistent with previous studies (Hao et al. 2018; Hille and Lambernd 2020; ling Guo et al. 2017). The GDP per capita income and FDI are insignificant while trade openness has positive significant impact on CE. This indicates that $1 \%$ increase in trade openness CE are increased by $1.89 \%$.

The panel B of table 7 shows short run relationship between variables. The short run results are different from long run. In the short run renewable energy development (RED), GDP per capita income (GDPP) and trade openness (TR) are significant impact on CE. The symmetric error correction (ECT) term is negative and significant, indicating the symmetric cointegration relationship. This implies that evidence supports earlier studies and suggest that there is convergence of system toward the equilibrium in the long-run after the any shock. Finally, the panel C shows diagnostic test to select the most appropriate method of estimations. We employ the Hausman test to select the more appropriate estimator. According to the Hausman test pooled mean group model (PMG) is more appropriate than the mean group estimate (MG).

Table 8 shows the nonlinear/asymmetric ARDL results. We observed that positive and negative shocks to RED, TIN, MR, and their interaction terms MR_RED and MR_TIN has not uniform impact on the CE over the sample period. The positive shocks to any variable have negative impact on $\mathrm{CE}$ while negative shocks to our core explanatory variable has positive impact. Panel A of Table 8 shows positive shocks to RED influence CE negatively, while negative shocks to RED influence CE positively. The findings suggest that any positive shocks to renewable energy development has negatively affect the CE and vice versa. Similarly, positive shocks to MR decrease the CE while negative shocks to MR increase $\mathrm{CE}$. This implies that market regulation policies are more friendly protect the natural environment and limiting carbon emissions. However, the difference between long-run and short run estimates is that long run coefficients are quite high as compare to short run coefficients. This indicates that the impact of renewable energy development, environmental related technologies, market based environmental regulation are more significant impact in long run as compare to short run.

Our results provide empirical evidence that renewable energy development, green technological innovation and market based regulation policies are the main mechanism to control and limiting the carbon emission in a sample of BRICS countries in the long run. Our findings are more consistent with the previous studies (Chen and Lee 2020; Hille and Lambernd 2020). 


\begin{tabular}{|c|c|c|c|c|c|c|}
\hline \multirow[b]{2}{*}{ Variables } & \multicolumn{3}{|c|}{ Mean Group Estimates } & \multicolumn{3}{|c|}{ Pooled Mean Group Estimates } \\
\hline & Coefficients & Standard Err. & Prob. & Coefficients & Standard Err. & Prob. \\
\hline \multicolumn{7}{|c|}{ Panel A: Long Run Estimates } \\
\hline $\mathrm{RED}^{+}$ & -1.176 & 0.531 & $(0.027)^{* *}$ & -1.347 & 0.102 & $(0.000)^{* * *}$ \\
\hline $\mathrm{RED}^{-}$ & 0.293 & 0.132 & $(0.026)^{* *}$ & 0.241 & 0.173 & $(0.168)$ \\
\hline $\mathrm{TIN}^{+}$ & 0.004 & 0.093 & $(0.963)$ & -0.150 & 0.040 & $(0.000)^{* * *}$ \\
\hline $\mathrm{TIN}^{-}$ & 0.041 & 0.155 & $(0.793)$ & 0.172 & 0.034 & $(0.000)^{* * *}$ \\
\hline $\mathrm{MR}^{+}$ & -1.670 & 0.936 & $(0.074)^{*}$ & -0.958 & 0.223 & $(0.000)^{* * *}$ \\
\hline $\mathrm{MR}^{-}$ & 0.650 & 0.389 & $(0.095)^{*}$ & 0.053 & 0.251 & $(0.834)$ \\
\hline MR_RED ${ }^{+}$ & -0.628 & 0.240 & $(0.009) * * *$ & -0.221 & 0.056 & $(0.000)^{* * *}$ \\
\hline MR_RED ${ }^{-}$ & 0.154 & 0.079 & $(0.050)^{* *}$ & 0.187 & 0.070 & $(0.010)^{* *}$ \\
\hline MR_TIN ${ }^{+}$ & 0.099 & 0.155 & $(0.522)$ & -0.209 & 0.041 & $(0.000)^{* * *}$ \\
\hline MR_TIN' & 0.134 & 0.221 & $(0.546)$ & 0.135 & 0.038 & $(0.001)^{* * *}$ \\
\hline GDPP & 0.431 & 0.327 & $(0.187)$ & 0.076 & 0.053 & $(0.161)$ \\
\hline TR & 0.038 & 0.037 & $(0.304)$ & 0.227 & 0.039 & $(0.000)^{* * *}$ \\
\hline FDI & -0.003 & 0.008 & $(0.734)$ & 0.004 & 0.004 & $(0.358)$ \\
\hline \multicolumn{7}{|c|}{ Panel B: Short Run Estimates } \\
\hline$\overline{\Delta \mathrm{RED}^{+}}$ & 0.900 & 2.014 & $(0.655)$ & 0.063 & 0.642 & $(0.922)$ \\
\hline$\triangle \mathrm{RED}^{-}$ & 1.256 & 0.471 & $(0.008) * * *$ & 0.813 & 0.375 & $(0.034)^{* *}$ \\
\hline$\Delta \mathrm{TIN}^{+}$ & 0.078 & 0.162 & $(0.629)$ & 0.082 & 0.102 & $(0.424)$ \\
\hline$\Delta \mathrm{TIN}^{-}$ & -0.153 & 0.141 & $(0.279)$ & -0.022 & 0.088 & $(0.802)$ \\
\hline$\Delta \mathrm{MR}^{+}$ & -0.882 & 0.955 & $(0.356)$ & -1.534 & 0.835 & $(0.071)^{*}$ \\
\hline$\Delta \mathrm{MR}^{-}$ & -1.200 & 0.780 & $(0.124)$ & -1.161 & 0.800 & $(0.152)$ \\
\hline$\Delta \mathrm{MR} \_\mathrm{RED}{ }^{+}$ & -0.343 & 0.212 & $(0.106)^{* *}$ & 0.350 & 0.295 & $(0.239)$ \\
\hline$\Delta \mathrm{MR} \mathrm{RED}^{-}$ & 0.386 & 0.219 & $(0.078)^{* *}$ & 0.221 & 0.272 & $(0.420)$ \\
\hline$\Delta \mathrm{MR}_{-\mathrm{TIN}^{+}}$ & 0.005 & 0.166 & $(0.977)$ & 0.067 & 0.076 & $(0.384)$ \\
\hline$\Delta \mathrm{MR}_{-} \mathrm{TIN}^{-}$ & 0.121 & 0.141 & $(0.392)$ & 0.055 & 0.065 & $(0.396)$ \\
\hline$\Delta \mathrm{GDPP}$ & 0.338 & 0.270 & $(0.211)$ & -0.072 & 0.147 & $(0.628)$ \\
\hline$\Delta \mathrm{TR}$ & 0.023 & 0.025 & $(0.371)$ & 0.054 & 0.021 & $(0.015)^{* * *}$ \\
\hline$\Delta \mathrm{FDI}$ & -0.004 & 0.005 & $(0.498)$ & 0.001 & 0.005 & $(0.763)$ \\
\hline ECT & -0.843 & 0.057 & $(0.005)^{* * *}$ & -0.251 & 0.151 & $(0.100)^{*}$ \\
\hline \multicolumn{7}{|c|}{ Panel C: Diagnostic Statistics } \\
\hline \multirow[t]{2}{*}{ Wald LR } & \multicolumn{3}{|c|}{$5.963^{\mathrm{a}}$} & $9.326^{\mathrm{a}}$ & & \\
\hline & \multicolumn{3}{|c|}{$(0.003)^{* * *}$} & $(0.000) * * *$ & & \\
\hline \multirow[t]{2}{*}{ Wald SR } & \multicolumn{3}{|c|}{$7.180^{\mathrm{b}}$} & $11.029^{\mathrm{a}}$ & & \\
\hline & \multicolumn{3}{|c|}{$(0.007) * *$} & $(0.000) * * *$ & & \\
\hline
\end{tabular}




\section{Conclusion and Policy Recommendations}

548 The enormous expansion of world trade and development increase the demand for fossil fuel energy. The rising fossil

549 fuel energy demand have had environmental consequences. There is need for protect the natural environment and limit

550 the carbon emissions for the sustainable environmental development. However, the development of renewable energy,

551 environmental and technological innovation, and market based environmental regulation polices play significant role

552 in sustainable environmental development. Thus, this paper examines the association the effect of renewable energy

553 development, market regulation and environmental regulation on carbon dioxide emissions in BRICS countries for

554 the period 1990-2020. Furthermore, we check the mediating role of environmental regulation. We used several

555 econometric methods including cross sectional dependency, panel unit root test, linear and nonlinear cointegration

556 test. Additionally, we employed the linear and nonlinear panel econometric methods to investigate the symmetric and

557 asymmetric relationship among the study variables.

558 Considering the symmetric approach, we found that renewable energy development (RED), technological

559 innovation (TIN) and market based environmental regulation policies (MR) play significant positive role in reducing

$560 \mathrm{CE}$ in the sample countries. Furthermore, the joint effect of MR*TIN and MR*RED lower the CE. In other words,

561 MR play significant positive mediating role between renewable energy development and technological innovation in

562 lowering the carbon emissions. Our empirical results support the idea that market based environmental policies are

563 key to control carbon emissions, renewable energy development and green technologies. GDP per capita income is

564 proxy for economic growth, is positive significant impact on CE. Similarly, trade openness is also positive and

565 significant impact on CE. This indicates that trade openness increase the emission pollution in the sample countries.

566 Inflow of foreign direct investment (FDI) has significant negative impact on CE in the short-run, while it is

567 insignificant impact in the long-run. The nonlinear specification, we found that positive shocks and negative shocks

568 in RED, TIN, MR, MR_RED and MR_TIN has not uniform influence CE. The positive shocks to the variable has

569 negative influence CE while positive shocks have negatively on CE. Meanwhile, the magnitude of coefficients is high

570 in the long run while low in the short run.

571 In the policy context, several policy recommendations were draw from the major findings of current study.

572 First; policymakers should more emphasized on the development of green technologies. The environmental related

573 technologies contribute directly and indirectly to reduce carbon emissions. Most emphasized on the green innovation

574 models and green innovative technologies through the environmental governance system. Second; policymakers

575 should more emphasized on the development of renewable energy resources with public and private partnership. Third,

576 implement market based environmental regulation policy. This can help to reduce the carbon emissions as well as

577 increase the revenues from more polluting industries or firms. 


\section{Declaration}

580 Ethical Approval

581 This study follows all ethical practices during writing. We confirmed that this manuscript has not been published

582 elsewhere and is not under consideration in any journal. Ethical approval and consent do not applicable for this study.

$583 \quad$ Funding

584 Not applicable

585 Competing Interest

586 The authors declare no competing interest

587 Author Contributions: The idea of original draft belongs to Shah Abbas. He designed overall experiment,

588 methodology and collect data with the help of Peng Gui and Chen Ai. The introduction and literature review section

589 written by Najabat Ali. Shah Abbas analyzed data and interpret the empirical outcomes. All the authors read and

590 approved the final manuscript.

591 Consent to Participate

592 Not applicable

593 Consent for Publication

$594 \quad$ Not applicable

$595 \quad$ Availability of Data and materials

596 The dataset used during the current study are available from corresponding author on reasonable request.

\section{References}

Aghion, P., P. Howitt. 1992. mA Model of Growth through Creative Destruction, nEconometrica: LX.

Ahmed, A., G. S. Uddin, K. Sohag. 2016. Biomass energy, technological progress and the environmental Kuznets curve: Evidence from selected European countries. Biomass and Bioenergy 90:202-208.

Al-Mahrouqi, M., A. Amin. 2014. Sultanate of Oman Renewable Readiness Assessment. The International Renewable Energy Agency (IRENA):1-68.

Althammer, W., E. Hille. 2016. Measuring climate policy stringency: a shadow price approach. International Tax and Public Finance 23 (4):607-639.

Altıntaş, H., Y. Kassouri. 2020. The impact of energy technology innovations on cleaner energy supply and carbon footprints in Europe: A linear versus nonlinear approach. Journal of Cleaner Production 276:124140.

Bächtold,

$$
\text { J. 2012. Russia }
$$

Renewable

Energy.

URL:

http://www. $\quad$ s-ge. com/de/filefieldprivate/files/53139/field_blog_public_files/14171 (02.12. 2015).

Balakrishnan, P., M. S. Shabbir, A. F. Siddiqi, X. Wang. 2020. Current status and future prospects of renewable energy: A case study. Energy Sources, Part A: Recovery, Utilization, and Environmental Effects 42 (21):2698-2703.

Banday, U. J., R. Aneja. 2020. Renewable and non-renewable energy consumption, economic growth and carbon emission in BRICS. International Journal of Energy Sector Management. 
Bank, W., U. N. D. o. Economic, S. Affairs. 2017. The potential of the blue economy: increasing long-term benefits of the sustainable use of marine resources for small island developing states and coastal least developed countries: World Bank.

Breyer, C., D. Bogdanov, A. Aghahosseini, A. Gulagi, M. Fasihi. 2020. On the techno-economic benefits of a global energy interconnection. Economics of Energy \& Environmental Policy 9 (1):83-103.

Brunel, C., A. Levinson. 2016. Measuring the stringency of environmental regulations. Review of Environmental Economics and Policy 10 (1):47-67.

Chen, L., P. De Lombaerde. 2014. Testing the relationships between globalization, regionalization and the regional hubness of the BRICs. Journal of Policy Modeling 36:S111-S131.

Chen, Y., C.-C. Lee. 2020. Does technological innovation reduce CO2 emissions? Cross-country evidence. Journal of Cleaner Production 263:121550.

Cheng, C., X. Ren, Z. Wang. 2019. The impact of renewable energy and innovation on carbon emission: An empirical analysis for OECD countries. Energy Procedia 158:3506-3512.

Churchill, S. A., J. Inekwe, R. Smyth, X. Zhang. 2019. R\&D intensity and carbon emissions in the G7: 1870-2014. Energy Economics 80:30-37.

Costa-Campi, M. T., P. del Rio, E. Trujillo-Baute. 2017. Trade-offs in energy and environmental policy: Elsevier.

Costantini, V., F. Crespi, G. Marin, E. Paglialunga. 2017. Eco-innovation, sustainable supply chains and environmental performance in European industries. Journal of Cleaner Production 155:141-154.

Cowan, W. N., T. Chang, R. Inglesi-Lotz, R. Gupta. 2014. The nexus of electricity consumption, economic growth and $\mathrm{CO} 2$ emissions in the BRICS countries. Energy policy 66:359-368.

Damette, O., A. C. Marques. 2019. Renewable energy drivers: a panel cointegration approach. Applied Economics 51 (26):2793-2806.

Dean, B., J. Dulac, K. Petrichenko, P. Graham. 2016. Towards zero-emission efficient and resilient buildings.: Global status report.

Dechezleprêtre, A., M. Sato. 2017. The impacts of environmental regulations on competitiveness. Review of Environmental Economics and Policy 11 (2):183-206.

Doğan, B., O. M. Driha, D. Balsalobre Lorente, U. Shahzad. 2021. The mitigating effects of economic complexity and renewable energy on carbon emissions in developed countries. Sustainable Development 29 (1):1-12.

Dogan, E., I. Ozturk. 2017. The influence of renewable and non-renewable energy consumption and real income on CO 2 emissions in the USA: evidence from structural break tests. Environmental Science and Pollution Research 24 (11):10846-10854.

Dogan, E., F. Seker. 2016. The influence of real output, renewable and non-renewable energy, trade and financial development on carbon emissions in the top renewable energy countries. Renewable and Sustainable Energy Reviews 60:1074-1085.

Dong, K., G. Hochman, Y. Zhang, R. Sun, H. Li, H. Liao. 2018. CO2 emissions, economic and population growth, and renewable energy: Empirical evidence across regions. Energy Economics 75:180-192. 
Du, K., Y. Cheng, X. Yao. 2021. Environmental regulation, green technology innovation, and industrial structure upgrading: The road to the green transformation of Chinese cities. Energy Economics 98:105247.

Dudley, B. 2018. BP statistical review of world energy. BP Statistical Review, London, UK, accessed Aug 6 (2018):00116.

Dumitrescu, E.-I., C. Hurlin. 2012. Testing for Granger non-causality in heterogeneous panels. Economic Modelling 29 (4):1450-1460.

Elavarasan, R. M., S. Afridhis, R. R. Vijayaraghavan, U. Subramaniam, M. Nurunnabi. 2020. SWOT analysis: A framework for comprehensive evaluation of drivers and barriers for renewable energy development in significant countries. Energy Reports 6:1838-1864.

Global, B. P. 2017. BP statistical review of world energy June 2017. Relatório, Disponível Em: http://Www. Bp. Com/En/Global/Corporate/Energy-Economics/Statistical-Review-Of-World-Energy.

Guo, R., Y. Yuan. 2020. Different types of environmental regulations and heterogeneous influence on energy efficiency in the industrial sector: Evidence from Chinese provincial data. Energy policy 145:111747.

Hao, Y., Y. Deng, Z.-N. Lu, H. Chen. 2018. Is environmental regulation effective in China? Evidence from city-level panel data. Journal of Cleaner Production 188:966-976.

Hatemi-J, A. 2020. Hidden panel cointegration. Journal of King Saud University-Science 32 (1):507-510.

Hille, E., W. Althammer, H. Diederich. 2020. Environmental regulation and innovation in renewable energy technologies: Does the policy instrument matter? Technological Forecasting and Social Change 153:119921.

Hille, E., B. Lambernd. 2020. The role of innovation in reducing South Korea's energy intensity: Regional-data evidence on various energy carriers. Journal of environmental management 262:110293.

Hu, H., N. Xie, D. Fang, X. Zhang. 2018. The role of renewable energy consumption and commercial services trade in carbon dioxide reduction: Evidence from 25 developing countries. Applied Energy 211:1229-1244.

Jardón, A., O. Kuik, R. S. Tol. 2017. Economic growth and carbon dioxide emissions: An analysis of Latin America and the Caribbean. Atmósfera 30 (2):87-100.

Khan, M. K., M. I. Khan, M. Rehan. 2020. The relationship between energy consumption, economic growth and carbon dioxide emissions in Pakistan. Financial Innovation 6 (1):1-13.

Kivyiro, P., H. Arminen. 2014. Carbon dioxide emissions, energy consumption, economic growth, and foreign direct investment: Causality analysis for Sub-Saharan Africa. Energy 74:595-606.

ling Guo, L., Y. Qu, M.-L. Tseng. 2017. The interaction effects of environmental regulation and technological innovation on regional green growth performance. Journal of Cleaner Production 162:894-902.

Liu, D., B. Xiao. 2018. Can China achieve its carbon emission peaking? A scenario analysis based on STIRPAT and system dynamics model. Ecological Indicators 93:647-657.

Maddala, G. S., S. Wu. 1999. A comparative study of unit root tests with panel data and a new simple test. Oxford Bulletin of Economics and statistics 61 (S1):631-652.

Meisen, P., S. Hawkins. 2009. Renewable energy potential of China: making the transition from coal-fired generation. Global Energy Network Institute (GENI), San Diego, California. 
Mert, M., G. Bölük, A. E. Çağlar. 2019. Interrelationships among foreign direct investments, renewable energy, and CO 2 emissions for different European country groups: a panel ARDL approach. Environmental Science and Pollution Research 26 (21):21495-21510.

Mi, Z., J. Meng, F. Green, D. M. Coffman, D. Guan. 2018. China's "exported carbon" peak: patterns, drivers, and implications. Geophysical Research Letters 45 (9):4309-4318.

Moutinho, V., M. Madaleno, R. Inglesi-Lotz, E. Dogan. 2018. Factors affecting CO2 emissions in top countries on renewable energies: a LMDI decomposition application. Renewable and Sustainable Energy Reviews 90:605-622.

Ouyang, X., X. Fang, Y. Cao, C. Sun. 2020. Factors behind CO2 emission reduction in Chinese heavy industries: Do environmental regulations matter? Energy policy 145:111765.

Pathak, L., K. Shah. 2019. Renewable energy resources, policies and gaps in BRICS countries and the global impact. Frontiers in energy 13 (3):506-521.

Pesaran, M. H. 2004. General diagnostic tests for cross-sectional dependence in panels. Empirical Economics:1-38. 2007. A simple panel unit root test in the presence of cross-section dependence. Journal of applied econometrics 22 (2):265-312.

Pesaran, M. H., Y. Shin. 1996. Cointegration and speed of convergence to equilibrium. Journal of econometrics 71 (1-2):117-143.

Pesaran, M. H., Y. Shin, R. J. Smith. 2001. Bounds testing approaches to the analysis of level relationships. Journal of applied econometrics 16 (3):289-326.

Pesaran, M. H., Y. Shin, R. P. Smith. 1999. Pooled mean group estimation of dynamic heterogeneous panels. Journal of the American statistical Association 94 (446):621-634.

Pesaran, M. H., R. Smith. 1995. Estimating long-run relationships from dynamic heterogeneous panels. Journal of econometrics 68 (1):79-113.

Piaggio, M., E. Padilla, C. Román. 2017. The long-term relationship between CO2 emissions and economic activity in a small open economy: Uruguay 1882-2010. Energy Economics 65:271-282.

REN21, R. 2018. Global Status Report. REN21 Secretariat. REN21 Secretariat.

Ren, S., X. Li, B. Yuan, D. Li, X. Chen. 2018. The effects of three types of environmental regulation on eco-efficiency: A cross-region analysis in China. Journal of Cleaner Production 173:245-255.

Ren, X., Z. Lu, C. Cheng, Y. Shi, J. Shen. 2019. On dynamic linkages of the state natural gas markets in the USA: Evidence from an empirical spatio-temporal network quantile analysis. Energy Economics 80:234-252.

Romer, P. 1990. Endogenous technical progress. Journal of political Economy 98 (5):71-103.

Saidi, K., A. Omri. 2020. Reducing CO2 emissions in OECD countries: Do renewable and nuclear energy matter? Progress in Nuclear Energy 126:103425.

Sarkodie, S. A., V. Strezov. 2019. Effect of foreign direct investments, economic development and energy consumption on greenhouse gas emissions in developing countries. Science of the Total Environment 646:862-871. 
Shahbaz, M., S. Khan, A. Ali, M. Bhattacharya. 2017. The impact of globalization on CO2 emissions in China. The Singapore Economic Review 62 (04):929-957.

Sheffield, P. E., P. J. Landrigan. 2011. Global climate change and children's health: threats and strategies for prevention. Environmental health perspectives 119 (3):291-298.

Shuai, C., L. Shen, L. Jiao, Y. Wu, Y. Tan. 2017. Identifying key impact factors on carbon emission: Evidences from panel and time-series data of 125 countries from 1990 to 2011. Applied Energy 187:310-325.

Sohag, K., R. A. Begum, S. M. S. Abdullah. 2015. Dynamic impact of household consumption on its CO 2 emissions in Malaysia. Environment, development and sustainability 17 (5):1031-1043.

Suzuki, M. 2015. Identifying roles of international institutions in clean energy technology innovation and diffusion in the developing countries: matching barriers with roles of the institutions. Journal of Cleaner Production 98:229-240.

Wang, B., Q. Wang, Y.-M. Wei, Z.-P. Li. 2018. Role of renewable energy in China's energy security and climate change mitigation: An index decomposition analysis. Renewable and Sustainable Energy Reviews 90:187194.

Wang, K.-L., B. Zhao, L.-L. Ding, Z. Miao. 2021. Government intervention, market development, and pollution emission efficiency: Evidence from China. Science of the Total Environment 757:143738.

Wang, Y., D. Zhang, Q. Ji, X. Shi. 2020. Regional renewable energy development in China: a multidimensional assessment. Renewable and Sustainable Energy Reviews 124:109797.

Wang, Z., Z. Yang, Y. Zhang, J. Yin. 2012. Energy technology patents-CO2 emissions nexus: an empirical analysis from China. Energy policy 42:248-260.

Westerlund, J. 2007. Testing for error correction in panel data. Oxford Bulletin of Economics and statistics 69 (6):709748.

Wolde-Rufael, Y., E. M. Weldemeskel. 2020. Environmental policy stringency, renewable energy consumption and $\mathrm{CO} 2$ emissions: Panel cointegration analysis for BRIICTS countries. International Journal of Green Energy 17 (10):568-582.

Wurlod, J.-D., J. Noailly. 2018. The impact of green innovation on energy intensity: An empirical analysis for 14 industrial sectors in OECD countries. Energy Economics 71:47-61.

Yang, G., D. Zha, X. Wang, Q. Chen. 2020. Exploring the nonlinear association between environmental regulation and carbon intensity in China: The mediating effect of green technology. Ecological Indicators 114:106309.

Yang, L., Z. Li. 2017. Technology advance and the carbon dioxide emission in China-Empirical research based on the rebound effect. Energy policy 101:150-161.

Zaidi, S. A. H., M. W. Zafar, M. Shahbaz, F. Hou. 2019. Dynamic linkages between globalization, financial development and carbon emissions: Evidence from Asia Pacific Economic Cooperation countries. Journal of Cleaner Production 228:533-543.

Zeng, S., Y. Liu, C. Liu, X. Nan. 2017. A review of renewable energy investment in the BRICS countries: History, models, problems and solutions. Renewable and Sustainable Energy Reviews 74:860-872. 
Zhou, C., S. Wang, K. Feng. 2018. Examining the socioeconomic determinants of CO2 emissions in China: A historical and prospective analysis. Resources, Conservation and Recycling 130:1-11.

761

Zhu, H., L. Duan, Y. Guo, K. Yu. 2016. The effects of FDI, economic growth and energy consumption on carbon emissions in ASEAN-5: evidence from panel quantile regression. Economic Modelling 58:237-248.

763 Zhu, S., C. He, Y. Liu. 2014. Going green or going away: Environmental regulation, economic geography and firms' strategies in China's pollution-intensive industries. Geoforum 55:53-65. 